\title{
Immunoglobulin-A detection and the investigation of clinical toxoplasmosis
}

\author{
BINDYA PATEL, YVONNE YOUNG, KIM DUFFY, R. P. TANNER, JULIE JOHNSON \\ and R. E. HOLLIMAN
}

Toxoplasma Reference Laboratory, Department of Medical Microbiology and Public Health Laboratory, St George's Hospital, London SW17 OQT

\begin{abstract}
Summary. Current serological methods for the investigation of Toxoplasma gondii infection are unreliable for the diagnosis of congenital disease, reactivated infection associated with the acquired immune deficiency syndrome (AIDS), or the determination of the date of onset of infection. An enzyme-linked immunosorbent assay (ELISA) and an immunosorbent agglutination assay (ISAGA) were developed for the detection of toxoplasma-specific immunoglobulin-A (IgA) and used to investigate patients in these three categories. The IgA ISAGA and IgA ELISA were found to be reproducible and specific tests. The IgA ISAGA demonstrated enhanced sensitivity. Measurement of IgA in patients with toxoplasmaassociated lymphadenopathy of known duration and AIDS patients with toxoplasma infection was of limited value. Detection of specific IgA by ISAGA was more sensitive than conventional methods for the diagnosis of congenital toxoplasmosis. We recommend the investigation of infant sera with IgA ISAGA. IgA estimation is not indicated in other clinical situations.
\end{abstract}

\section{Introduction}

The detection of specific IgG and IgM is widely used in the diagnosis of viral, bacterial and parasitic infection. Recently, measurement of specific $\operatorname{IgA}$ has been shown to be of value in investigations of infected patients. ${ }^{1}$ In toxoplasmosis, detection of specific IgA may be useful in a number of clinical settings where current serological methods are unreliable. Congenital toxoplasmosis is associated with maternal parasitaemia, infection of the placenta and subsequent infection of the fetus. Parasitaemia is usually limited to a period of 1-3 weeks duration. Furthermore, the risk of maternal-fetal transfer of infection rises as the gestational age at the time of exposure progresses, whereas the incidence of severe disease falls. ${ }^{2}$ Consequently, precise dating of the onset of maternal infection would permit an accurate estimation of the risk of congenital infection and fetal damage. However, repeated IgG estimation to demonstrate seroconversion is rarely performed outside an ante-natal screening programme and in many countries the value of this approach is not established. ${ }^{3}$ Measurement of specific IgM gives some indication of recent infection but the persistence of IgM can be protracted, depending on the sensitivity of the assay employed and the individual immune response. ${ }^{4}$ As a result, the current methods do not permit the precise determination of the date of onset of maternal infection.
The diagnosis of congenital infection is problematic. Passively acquired IgG of maternal origin may persist in the infant's blood for $\geqslant 6$ months, depending on the original titre at delivery, and detection of specific IgM is relatively insensitive, so that the absence of $\operatorname{IgM}$ in the neonate does not exclude congenital infection. ${ }^{5}$ Rapid diagnosis of congenital infection is required as there is some evidence that treatment given in the early post-natal period may reduce the incidence of ocular disease in later life. ${ }^{6}$ Cerebral toxoplasmosis associated with the acquired immune deficiency syndrome (AIDS) most often results from secondary reactivation of the patient's previously quiescent infection. Specific IgG is present but rising IgG titres and specific IgM are rarely detected. The absence of specific IgG excludes cerebral toxoplasmosis but conventional serology cannot produce a definitive diagnosis. ${ }^{\text {? }}$

A number of techniques have been applied to the detection of IgA in toxoplasma infection, including the enzyme-linked immunosorbent assay (ELISA), ${ }^{8,9}$ the immunosorbent agglutination assay (ISAGA), ${ }^{10} \mathrm{im}-$ munoblotting ${ }^{11}$ and Western blotting. ${ }^{12}$ The relative merits of these tests have not been established. We have developed two methods for the measurement of toxoplasma-specific IgA and compared the findings of these assays with those of conventional serological tests for the investigation of neonates, AIDS patients and for estimating the duration of toxoplasma infection. 


\section{Materials and methods}

\section{$\operatorname{IgA}$ ELISA}

To each well of a flexible PVC microtitration plate was added $100 \mu \mathrm{l}$ of a 1 in 600 dilution $(9 \cdot 7 \mu \mathrm{g} / \mathrm{ml})$ of rabbit anti-human IgA monoclonal antibody (Dakopatts, Denmark) diluted in $50 \mathrm{~mm}$ carbonate-bicarbonate buffer, $\mathrm{pH} 9 \cdot 6$; the plate was covered and incubated in a moist chamber at $37^{\circ} \mathrm{C}$ for $24 \mathrm{~h}$. After incubation, the plate was washed four times with phosphate buffered saline (PBS) containing Tween 20 $0.05 \%$ (PBST) with a mechanical plate washer and residual PBST was removed by tapping gently on to absorbent paper towels; $100 \mu \mathrm{l}$ of a 1 in 500 dilution of patient's serum in PBST containing bovine serum albumin $1 \%$ (PBST-BSA) was then added to duplicate wells on the plate. The plate was incubated for $2 \mathrm{~h}$ at $37^{\circ} \mathrm{C}$ and, after washing again, $100 \mu \mathrm{l}$ of a 1 in 30 dilution of antigen-conjugate in PBST-BSA was added to all wells and the plate was incubated for a further hour. The antigen-conjugate consisted of a 35$\mathrm{kDa}$ surface antigen of toxoplasma attached to a monoclonal antibody (HAb) specifically recognising this antigen which, in turn, was conjugated to horseradish peroxidase. ${ }^{13}$ After further washing, $100 \mu$ of freshly prepared substrate solution was added to all wells and the plate was left in the dark at room temperature for $45 \mathrm{~min}$. The substrate consisted of $12 \mathrm{ml}$ of sodium acetate-citric acid buffer $(100 \mathrm{~mm}$; $\mathrm{pH}$ 6), 3.3.5.5 tetramethylbenzidine (TMB) $120 \mu \mathrm{l}$ and $12 \mu \mathrm{l}$ of hydrogen peroxide $6 \%$. The reaction was stopped by the addition of $25 \mu \mathrm{l}$ of $2 \mathrm{M} \mathrm{H}_{2} \mathrm{SO}_{4}$ to each well and mixing thoroughly. The absorbance was then measured at $450 \mathrm{~nm}$ with a spectrophotometer.

\section{Positive control and derivation of EIU values}

The St George's Hospital internal positive control consists of pooled sera which have been proven to give titres of 1 in 128-512 in the dye test and to be negative for both $\operatorname{IgM}$ and IgA. This serum was used as the negative control for IgA and was included in each assay run. An IgA-positive serum was selected as a reference standard and assigned an arbitrary value of 100 units (EIU). This is the National Control prepared from a pool of serum collected from patients with acute toxoplasmic lymphadenopathy. It is dispensed in $0.2-\mathrm{ml}$ volumes into ampoules, freeze-dried and is standardised against the International Control provided by the WHO, Copenhagen. The total contents of the ampoule contain, by definition, 2000 International Units (IU) of anti-toxoplasma serum. Running this reference serum in each assay enabled the amount of IgA in each serum, relative to this standard, to be calculated from the equation:

IgA level in sample $=$

$$
\frac{\text { A sample }- \text { A neg control }}{\text { A positive control }- \text { A negative control }} \times 100 \text { EIU }
$$

where $A$ is the absorbance reading at $450 \mathrm{~nm}$.

\section{Establishing the cut-off point}

A series of 176 sera, negative for both IgG and IgM toxoplasma-specific antibodies, were assayed in duplicate over four separate assays. The mean absorbance value and SD for these sera was calculated. Four standard deviations above the mean for negative sera was selected as the cut-off point and this critical value was used for all further assays.

\section{Establishment of a one well screen immunosorbent agglutination assay (ISAGA)}

An IgA ISAGA was adapted from a commercial IgM ISAGA (bioMérieux, France). Wells of polystyrene microtitration plates were coated with different concentrations $(9 \cdot 7,8 \cdot 3,7 \cdot 25,6 \cdot 4,5 \cdot 8$ and $0.58 \mu \mathrm{g} / \mathrm{ml})$ of anti-human IgA MAb (Dakopatts, Denmark) diluted in carbonate-bicarbonate buffer, $\mathrm{pH} 9 \cdot 6$, and incubated for $24 \mathrm{~h}$ at $4^{\circ} \mathrm{C}$. The plates were washed three times for 5 min each in PBS and post-coated with bovine serum albumin (BSA) $1 \%$ in PBS with sodium azide $0.1 \%$ for $24 \mathrm{~h}$ at $4^{\circ} \mathrm{C}$. After a further washing step, the plates were used immediately. Ten sera IgApositive by ELISA, 10 sera IgA-negative (IgMnegative) by ELISA, UK National Standard and P14 (St George's Hospital internal positive control for the dye test) were used to screen the plates. One hundred $\mu$ l of a 1 in 20 dilution of serum in PBS was added to each well and plates were incubated for $3 \mathrm{~h}$ at $37^{\circ} \mathrm{C}$. After washing three times for $5 \mathrm{~min}$ in PBS containing Tween $200.5 \%, 100-\mu \mathrm{l}$ suspensions of formalin-killed parasites at a concentration of $1.25 \times 10^{4} / \mathrm{ml}$ were added. The plates were incubated for $24 \mathrm{~h}$ at $37^{\circ} \mathrm{C}$ in a moist chamber and then observed for agglutination. A smooth button of parasites at the bottom of the well was recorded as a negative result and given a score of 0 ; a homogeneously distributed carpet of agglutinated parasites was regarded as being a positive result and given a score of 4 .

\section{Reproducibility}

To assess the variability of the IgA ELISA microtitration plate and the conditions across the plate, the assay was performed with identical reagents in all 96 wells with a serum sample found to produce a positive IgA result. Inter- and intra-batch variation was assessed by testing four sera twice on 10 separate occasions. The four sera were selected to give results ranging from negative to strongly positive. Standard deviations within batches and between batches were calculated and repeatability was assessed by determining the coefficient of repeatability. ${ }^{14}$

Homogeneous coating of IgA ISAGA plates with anti-human IgA MAb was assessed by testing the 22 selected sera four times each on the same plate at each concentration of coating antibody.

\section{Specificity}

The specificity of each assay was evaluated with 
selected sera; 100 samples negative for toxoplasmaspecific IgM and IgG were tested. Sera negative for toxoplasma-specific IgG and IgM but with the potential to produce false positive results were processed. These samples comprised five positive for rheumatoid factor, five positive for anti-nuclear factor, five positive for hepatitis A virus (HAV)-specific IgM, five positive for cytomegalovirus (CMV)-specific IgM, five positive for Epstein-Barr virus (EBV)-specific IgM, five haemolysed and five jaundiced sera. Ten toxoplasmaspecific IgG- and IgM-negative samples were heat inactivated at $56^{\circ} \mathrm{C}$ for $3 \mathrm{~h}$ and then tested by each $\operatorname{IgA}$ assay. Potential false negative reactions were assessed by freeze-thawing 10 specimens originally found to be IgA ELISA/ISAGA positive for a total of five cycles and re-testing them by each assay.

\section{Sensitivity}

The sensitivity of the IgA ELISA was assessed by testing a series of 856 sera, all toxoplasma-specific IgG-positive but with varying amounts of specific IgM ranging from negative (IgM ELISA negative, IgM ISAGA negative) and low positive (ELISA negative, ISAGA positive) to high positive (ELISA positive, ISAGA positive). ${ }^{4}$ The comparative sensitivity of the IgA ELISA and ISAGA was investigated by selecting six sera positive by each assay; $5 \%$ serial dilutions in PBS of each sample were prepared and each series was tested by both IgA assays.

\section{Further serological tests}

Toxoplasma-specific IgM was measured by a $\mu$ chain capture ELISA and IgM ISAGA as previously described $^{4}$ to detect recent infection. Exposure to Toxoplasma gondii was assessed by the dye test and latex agglutination test. ${ }^{15}$ Positive samples were defined as dye test $\geqslant 4 \mathrm{IU}$ and a latex agglutination test titre $\geqslant 16$. Samples producing discordant findings were further assessed by the direct agglutination test and classified as seropositive if the result was $\geqslant 4 \mathrm{U} .{ }^{16}$

\section{Clinical samples}

The association between toxoplasma-specific IgA and duration of infection was investigated by testing patients with cervical lymphadenopathy of defined duration and serological evidence of recent toxoplasma infection. Post-natal serum samples taken from congenitally infected babies and their mothers were tested for toxoplasma-specific IgA, as were specimens from children shown to be uninfected. All the mothers had recent toxoplasma infection (IgM ELISA and IgM ISAGA positive); congenital infection was confirmed by the persistence of specific IgG at the age of 1 year. Uninfected children were defined as individuals who showed a complete loss of toxoplasma-specific antibody before the age of 1 year.

The role of IgA measurement in the diagnosis of cerebral toxoplasmosis was studied by testing AIDS patients who had been exposed to $T$. gondi. Individuals with cerebral toxoplasmosis associated with primary infection or secondary reactivation were investigated, as were patients with chronic toxoplasma infection but no evidence of clinical disease. Cerebral toxoplasmosis was diagnosed on the basis of compatible clinical and radiological findings with a significant response to specific antiparasitic therapy. All patients had serological evidence of exposure to $T$. gondii (dye test $\geqslant 4$ IU). Patients tested in the 3 months before the onset of illness and found to lack antibody to toxoplasma at that time were defined as having primary infection. Those with detectable specific IgG before the onset of disease were defined as having secondary reactivation of infection.

\section{Results}

The mean IgA ELISA absorbance value recorded for 176 sera, negative for toxoplasma-specific IgG and IgM, was 0.00032 and the SD 0.000583 . Four SD above the mean was calculated to be 0.024 which represented the critical value between negative and positive findings.

The reproducibility of the assay was assessed with identical reagents in all 96 wells of an ELISA plate. The variation across the plate was $7 \cdot 2 \%$. Four sera, selected to represent a range of IgA content, were assayed on 10 separate occasions to establish the "within-batch" and "between-batch" variability of the ELISA. The results shown in table I demonstrate that the precision of the assay was inversely proportional to the amount of IgA in the sample.

Table I. Within-batch and between batch variation in absorbance values for sera tested by IgA ELISA

\begin{tabular}{lcccccc}
\hline & \multirow{2}{*}{$\begin{array}{c}\text { Mean } \\
\text { IgA result }\end{array}$} & \multicolumn{2}{c}{ Within-batch } & & \multicolumn{2}{c}{ Between-batch } \\
\cline { 3 - 4 } \cline { 6 - 7 } & absorbance value & SD & Repeatability & & SD & Repeatability \\
\cline { 3 - 4 } Negative & -0.0118 & 0.0018 & 0.0050 & & 0.0033 & 0.0091 \\
Equivocal & 0.0273 & 0.0032 & 0.0089 & & 0.0037 & 0.0103 \\
Low positive & 0.0776 & 0.0046 & 0.0128 & & 0.0045 & 0.0125 \\
High positive & 0.6536 & 0.0124 & 0.0344 & & 0.0230 & 0.0638 \\
\hline
\end{tabular}


Table II. IgA measurement by $\alpha$-chain capture ELISA in sera positive for toxoplasma-specific IgG but with differing levels of IgM

\begin{tabular}{|c|c|c|c|}
\hline $\begin{array}{l}\text { IgM assay } \\
\text { results }\end{array}$ & $\begin{array}{l}\text { Number of } \\
\text { specimens } \\
\text { tested }\end{array}$ & IgA detected & IgA reactive $(\%)$ \\
\hline $\begin{array}{l}\text { ELISA - } \\
\text { ISAGA - }\end{array}$ & 359 & 5 & 1.4 \\
\hline $\begin{array}{l}\text { ELISA - } \\
\text { ISAGA } \pm\end{array}$ & 157 & 9 & $5 \cdot 7$ \\
\hline $\begin{array}{l}\text { ELISA - } \\
\text { ISAGA + }\end{array}$ & 169 & 37 & 21.9 \\
\hline $\begin{array}{l}\text { ELISA } \pm \\
\text { ISAGA }+\end{array}$ & 23 & 8 & $34 \cdot 8$ \\
\hline $\begin{array}{l}\text { ELISA + } \\
\text { ISAGA+ }\end{array}$ & 148 & 96 & $64 \cdot 9$ \\
\hline
\end{tabular}

+ , positive; - , negative; \pm , equivocal.

The optimum concentration of anti-human $\operatorname{IgA}$ coating antibody in the IgA ISAGA was $0.58 \mu \mathrm{g} / \mathrm{ml}$ in carbonate-bicarbonate buffer. Homogeneous coating of the plate was confirmed by the finding of $\operatorname{IgA}$ positive and -negative samples producing the expected score of 4 or 0 , respectively, in each test.

None of the 100 samples negative for toxoplasmaspecific IgG or IgM produced a positive IgA reaction in ELISA or ISAGA. Similarly, none of the samples selected for the potential to generate false positive reactions produced a positive IgA finding by either
Table III. Toxoplasma-specific IgA detection in serial dilutions of sera tested by ISAGA and ELISA

\begin{tabular}{ccc}
\hline \multirow{2}{*}{$\begin{array}{c}\text { Sample } \\
\text { no. }\end{array}$} & Greatest dilution associated with detectable IgA $(\%)$ \\
\cline { 2 - 3 } & ELISA & ISAGA \\
\hline 1 & 60 & 95 \\
2 & 60 & 95 \\
3 & 50 & 95 \\
4 & 25 & 95 \\
5 & 20 & 65 \\
6 & 20 & 60 \\
\hline
\end{tabular}

assay. Freeze-thawing did not effect the IgA ELISA or ISAGA results.

\section{Sensitivity}

IgA ELISA findings in samples containing toxoplasma-specific IgG and varying amounts of IgM are shown in table II. The percentage of specimens with detectable IgA was directly proportional to the amount of toxoplasma-specific IgM.

The results of testing serial dilutions of six samples by IgA ELISA and ISAGA are shown in table III. In each series the IgA ISAGA remained reactive at a higher dilution than did the IgA ELISA, indicating the superior sensitivity of the former assay.

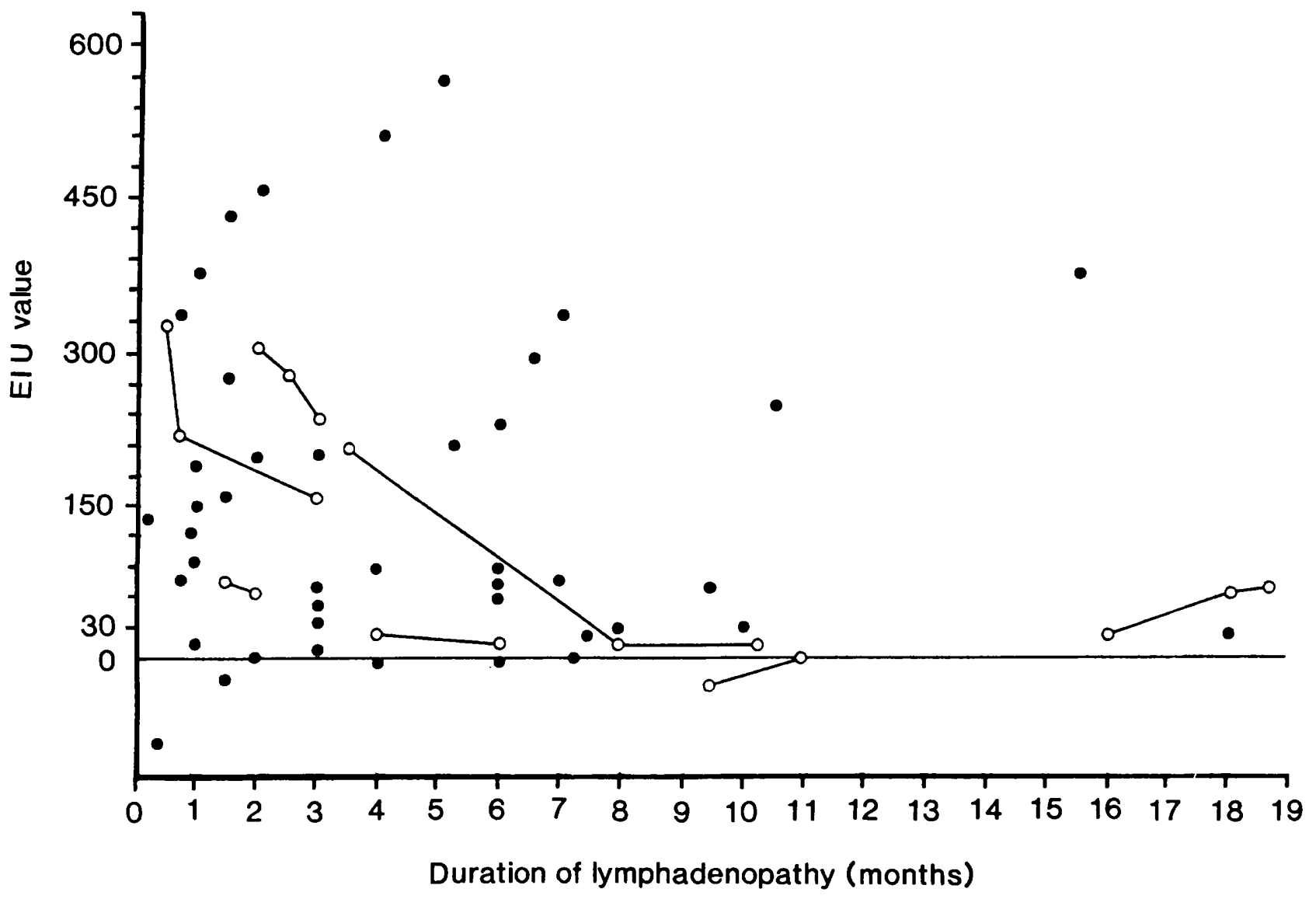

Figure. Relationships of EIU values for toxoplasma-specific IgA ELISA to duration of lymphadenopathy: $\bigcirc-O$, sequential sera from individual patients; single investigations. 
Table IV. Results of toxoplasma-specific IgA and IgM detected by ELISA and ISAGA in the sera of congenitally infected babies

\begin{tabular}{l|ccc}
\hline \multirow{2}{*}{$\begin{array}{l}\text { IgA } \\
\text { results }\end{array}$} & \multicolumn{3}{|c}{ Number of sera that gave IgM } \\
\cline { 2 - 4 } & $\begin{array}{c}\text { ELISA+ } \\
\text { ISAGA+ }\end{array}$ & $\begin{array}{c}\text { ELISA- } \\
\text { ISAGA+ }\end{array}$ & $\begin{array}{c}\text { ELISA- } \\
\text { ISAGA- }\end{array}$ \\
\hline $\begin{array}{l}\text { ELISA+ } \\
\text { ISAGA+ }\end{array}$ & 2 & 0 & 0 \\
$\begin{array}{l}\text { ELISA- } \\
\text { ISAGA+ } \\
\begin{array}{l}\text { ELISA- } \\
\text { ISAGA- }\end{array}\end{array}$ & 1 & 3 & 6 \\
\hline
\end{tabular}

\section{Ig $A$ and the duration of infection}

A total of 60 specimens from 49 patients with lymphadenopathy of defined duration and serological evidence of recent toxoplasmosis were investigated. Duration of symptoms compared to IgA ELISA findings are shown in the figure. Five series of sera associated with infection acquired within 6 months of testing showed a decreasing level of specific IgA as the duration of symptoms increased. The magnitude of the IgA response at a defined duration of lymphadenopathy was found to be highly variable, so that it was not possible to predict the date of onset of infection from a single IgA estimation.

\section{IgA and the diagnosis of congenital toxoplasmosis}

Seventeen babies with congenital toxoplasmosis were investigated as well as a further 17 uninfected children delivered by mothers who suffered acute toxoplasma infection associated with pregnancy. In 12 of the children with congenital infection, toxoplasmaspecific IgA was detected by ISAGA when first tested after birth, compared to two positive results by IgA ELISA. None of the uninfected babies were found to have toxoplasma-specific IgA when tested by ELISA, but one had a reactive IgA ISAGA result 2 days after delivery. Subsequent investigation of the child aged 3 months did not detect IgA by either assay. Seven infected babies had detectable specific IgM (four positive by ELISA; seven positive by ISAGA) and none of the uninfected infants was IgM reactive. A comparison of toxoplasma-specific IgA and IgM in congenitally infected babies measured by ELISA and ISAGA is presented in table IV.

Post-natal examination of 17 mothers who delivered babies with congenital toxoplasmosis showed that 11 had detectable IgA (nine positive by ELISA, 11 positive by ISAGA). Of 17 mothers with acute toxoplasmosis associated with pregnancy who delivered uninfected children, five had detectable IgA in the post-natal period (two positive by ELISA, five positive by ISAGA).

\section{IgA and cerebral toxoplasmosis with AIDS}

A total of 20 patients with confirmed cerebral toxoplasmosis with AIDS and 20 AIDS patients with serological findings indicating exposure to toxoplasma but no evidence of cerebral disease were studied. Of the 20 cases of cerebral toxoplasmosis, three were associated with primary toxoplasma infection and 17 followed reactivation of a previously quiescent infection.

The results of toxoplasma-specific IgA and IgM studies with ELISA and ISAGA are presented in table V. All patients with cerebral toxoplasmosis and primary infection had specific IgM and IgA detected by ISAGA and ELISA. Patients with reactivated infection and cerebral disease did not show significantly different IgA or IgM findings compared to AIDS patients without clinical disease.

\section{Discussion}

Toxoplasmosis may be acquired by ingestion of the parasite, or by congenital transmission or it may result from reactivation of a previously quiescent chronic infection in immunocompromised individuals. ${ }^{17}$ Studies of animals infected by ingestion of $T$. gondii have demonstrated the production of secretory IgA in intestinal fluid, ${ }^{18}$ and $\operatorname{IgA}$ can be detected in the peripheral blood of human patients with acute toxoplasmosis. ${ }^{11}$ We have confirmed the findings of others that specific IgA can be measured by ELISA or

Table V. Toxoplasma-specific IgA and IgM assays of AIDS patients with cerebral disease or quiescent infection

\begin{tabular}{|c|c|c|c|c|c|}
\hline \multirow{2}{*}{$\begin{array}{l}\text { Clinical } \\
\text { status }\end{array}$} & \multirow{2}{*}{$\begin{array}{l}\text { Number } \\
\text { of patients }\end{array}$} & \multicolumn{2}{|c|}{ IgA-positive } & \multicolumn{2}{|c|}{ IgM-positive } \\
\hline & & ELISA & ISAGA & ELISA & ISAGA \\
\hline $\begin{array}{l}\text { Cerebral toxoplasmosis } \\
\text { associated with primary } \\
\text { infection }\end{array}$ & 3 & 3 & 3 & 3 & 3 \\
\hline $\begin{array}{l}\text { Cerebral toxoplasmosis } \\
\text { associated with secondary } \\
\text { activation of infection }\end{array}$ & 17 & 0 & 5 & 0 & 3 \\
\hline $\begin{array}{l}\text { Asymptomatic quiescent } \\
\text { toxoplasmosis }\end{array}$ & 20 & 1 & 3 & 1 & 1 \\
\hline
\end{tabular}


ISAGA. The within-batch and between-batch variation of the IgA ELISA findings was sufficiently small to permit the generation of clinically useful results. Similarly, the reproducibility of IgA ISAGA results was acceptable for diagnostic application.

The dye test is regarded as the reference assay for the assessment of the sensitivity and specificity of the measurement of toxoplasma-specific IgG. However, there is no such "gold standard" defined for the other immunoglobulin classes including IgA. Quantitative assessment of the precision of a toxoplasma-specific IgA test cannot be undertaken. Qualitative evaluation can be performed by the comparison of IgA findings with established serological methods. The specificity of both the IgA ELISA and ISAGA methods was confirmed by these parameters. No false positive reactions were recorded, despite the evaluation of a large number of samples and the inclusion of specimen types which have been associated with non-specific reactions in other serological assays. We did not find a significant difference in the specificity of the two $\operatorname{IgA}$ assays.

The IgM ISAGA has been shown to detect toxoplasma-specific IgM with greater sensitivity than the IgM ELISA. Consequently, a semi-quantitative measurement of specific IgM can be made by testing a sample of each method. A specimen producing a positive finding by ELISA and ISAGA will contain a larger amount of specific IgM than a specimen reactive by ISAGA alone. ${ }^{4}$ We have shown that the percentage of patients with detectable toxoplasma-specific IgA is directly proportional to the level of specific IgM in the patient's blood. However the IgA ELISA result was negative in a third of samples with high levels of specific IgM. These findings suggest that IgA detectable by ELISA is associated with acute toxoplasma infection but that the sensitivity of the IgA ELISA may be relatively low. This was confirmed by the direct comparison of IgA ELISA and ISAGA results with dilution series of IgA-reactive sera, which demonstrated the superior sensitivity of the ISAGA method. The enhanced sensitivity of the IgA ISAGA compared to the IgA ELISA may reflect the higher concentration of membrane antigens presented in the former assay. Detailed studies have shown that the early immune response, of which IgM and IgA are components, is primarily directed against membrane antigens of the parasite whereas antibody-recognising cytoplasmic antigens are formed as the immune response matures..$^{11,12}$

The optimum method for assessing the relationship between $\operatorname{IgA}$ and the duration of infection would be to test serial samples drawn from a patient with a precisely dated dye test seroconversion. As most cases of toxoplasma infection are asymptomatic and pass unrecognised without investigation, few seroconversion series are available. Small numbers of these samples have been obtained from laboratory workers infected in occupational accidents ${ }^{11}$ or pregnant women identified during routine ante-natal screening for toxoplasmosis. ${ }^{19}$ Due to the scarcity of seroconversion-related series of specimens, we and other groups have utilised patients with serological evidence of recent toxoplasma infection and associated lymphadenopathy of established duration. ${ }^{19}$ Although readily available, these specimens are less reliable than documented seroconversion samples, as asymptomatic toxoplasmosis may co-exist with lymphadenopathy of a separate pathogenesis. Furthermore, there may be variation in the periods between acquisition of infection, onset of symptoms and patient recognition of the abnormality. Consequently, the results of $\operatorname{IgA}$ measurement in cases of toxoplasma-associated lymphadenopathy must be viewed with caution. An inverse relationship between the specific IgA level and the duration of symptoms was demonstrated and confirms the findings of others. ${ }^{19} \mathrm{We}$ found significant variation in the IgA level at a defined duration of infection. As the IgA ELISA results have been shown to be highly reproducible, this diversity is likely to reflect the variation in the host immune response to toxoplasma infection. In our experience it is not possible to date precisely the onset of infection by IgA estimation. As with IgM assessment, the presence of specific IgA indicates recent infection but the persistence of $\operatorname{Ig} A$ is variable, depending on the sensitivity of the assay and the individual immune response. IgA estimation is unlikely to confer additional benefit, compared with IgM measurement, in the determination of the date of onset of maternal toxoplasmosis. Novel methods for estimating the duration of toxoplasma infection, such as measurement of IgG avidity, require detailed evaluation.

In our hands, the IgA ISAGA was the most sensitive test for the investigation of 17 babies with congenital toxoplasmosis, correctly identifying 12 cases, compared to seven by IgM ISAGA, four by IgM ELISA and two by IgA ELISA. These results confirm the enhanced sensitivity of ISAGA methodology compared to ELISA. Other workers have demonstrated the comparable sensitivity of an IgA ISAGA and an enzyme-linked immunofiltration assay in the diagnosis of congenital toxoplasmosis and the superior sensitivity of ISAGA when applied to samples from pregnant women. ${ }^{10}$ Decoster et al. found an IgA ISAGA technique to be more sensitive than an IgA ELISA when investigating babies for toxoplasma infection. ${ }^{8}$ This group did not record any IgA ISAGA positive findings in non-infected infants, whereas one positive result was noted in our series. This specimen was taken only 2 days after delivery, and maternal blood reaching the infant via a placental defect could result in a positive IgA ISAGA reaction at this age. These findings emphasise the importance of confirmatory testing of babies found to be toxoplasmaspecific IgM or IgA positive in the neonatal period. Further studies are required to define the specificity of the IgA ISAGA in the diagnosis of congenital toxoplasmosis. Until such studies are completed, we recommend parallel testing of infant samples by both 
IgM and IgA ISAGA and the confirmation of positive findings by the persistence of specific IgG at the age of 12 months.

Post-natal investigation of mothers with acute toxoplasmosis associated with the pregnancy showed that women who delivered congenitally infected children were more often toxoplasma-specific IgA reactive than women whose children were not infected. As the duration of IgA production is limited, ${ }^{19}$ women who are IgA positive in the post-natal period are likely to have acquired toxoplasmosis later in pregnancy than those who have no detectable IgA. It has been established that maternal-fetal transmission of toxoplasma infection is greater in the third trimester of pregnancy than the first. ${ }^{20}$ Due to individual variation in the duration and magnitude of the immune response, post-natal maternal IgA estimation is not a precise indication of congenital infection, and investigation of the child is mandatory. Maternal prenatal IgA testing has not been assessed.

\section{References}

1. Cranage MP, Kennedy D, Venters JL, Gray JJ. IgA responses during human cytomegalovirus infection in cardiac transplant recipients: concurrent detection of IgA and IgM antiglobulins. Serodiagn Immunother Infect Dis 1988; 2: 301-309.

2. Desmonts $\mathrm{G}$, Couvreur J. Toxoplasmosis in pregnancy and its transmission to the fetus. Bull NY Acad Med 1974; 50: 146-159.

3. Anon. Antenatal screening for toxoplasmosis in the UK. (Editorial). Lancet 1990; 336: 346-348.

4. Duffy KT, Wharton PJ, Johnson JD, New L, Holliman RE. Assessment of immunoglobulin-M immunosorbent agglutination assay (ISAGA) for detecting toxoplasma specific IgM. J Clin Pathol 1989; 42: 1291-1295.

5. Holliman RE, Johnson JD. The post-natal serodiagnosis of congenital toxoplasmosis. Serodiagn Immunother Infect Dis $1989 ; 3$ : 323-327.

6. Wilson CB, Remington JS, Stagno S, Reynolds DW. Development of adverse sequelae in children born with subclinical congenital toxoplasma infection. Pediatrics 1980; 66: 767-774.

7. Holliman RE. Toxoplasmosis and the acquired immune deficiency syndrome. J Infect 1988; 16: 121-128.

8. Decoster A, Darcy F, Caron A, Capron A. IgA antibodies against P30 as markers of congenital and acute toxoplasmosis. Lancet 1988; 2: 1104-1107.

9. van Loon AM, van der Logt JTM, Heessen FWA, van der Veen J. Enzyme-linked immunosorbent assay that uses labelled antigen for detection of immunoglobulin $\mathbf{M}$ and $\mathbf{A}$ antibodies in toxoplasmosis: comparison with indirect immunofluorescence and double-sandwich enzyme-linked immunosorbent assay, $J$ Clin Microbiol 1983; 17: 997-1004.

10. Pinon JM, Thoannes $\mathbf{H}$, Pouletty PH, Poirriez J, Damiens J, Pelletier P. Detection of IgA specific for toxoplasmosis in
Patients with primary toxoplasmosis associated with AIDS were found consistently to produce specific IgA and IgM detectable by ELISA and ISAGA. There were no significant differences in the frequency of detectable IgA between AIDS patients with chronic quiescent toxoplasmosis and those with secondary reactivation resulting in cerebral disease. Consequently we confirm the opinion of other groups that toxoplasma-specific IgA measurement is not useful in AIDS patients. ${ }^{19,21}$

We have shown that toxoplasma-specific IgA can be measured precisely by ELISA or ISAGA. We recommend that IgA ISAGA be used for the investigation of congenital toxoplasmosis because of the enhanced sensitivity of this assay. IgA estimation is not indicated in other clinical situations:

The development of the IgA ISAGA and its application to the investigation of congenital toxoplasmosis was supported by a grant from Birthright. We are grateful to Mrs D. Lyndon for preparing the manuscript.

serum and cerebrospinal fluid using a non-enzymatic IgAcapture assay. Diagn Immunol 1986; 4: 223-227.

11. Partanen P, Turunen HJ, Paasivvo RA, Leinikki PO. Immunoblot analysis of Toxoplasma gondii antigens by human immunoglobulins $\mathrm{G}, \mathrm{M}$, and $\mathrm{A}$ antibodies at different stages of infection. J Clin Microbiol 1984; $20: 133-135$.

12. Huskinson $J$, Thulliez $P$, Remington JS. Toxoplasma antigens recognized by human immunoglobulin $\mathrm{A}$ antibodies. $J$ Clin Microbiol 1990; 28 : 2632-2636.

13. Payne RA, Joynson DHM, Balfour AH et al. Public Health Laboratory Service enzyme linked immunosorbent assay for detecting toxoplasma specific IgM antibody. $J$ Clin Pathol 1987; 40: 276-281.

14. Bland M. An introduction to medical statistics. Oxford, Oxford Medical Publications. 1987: Oxford, 276-278.

15. Holliman RE, Johnson J, Duffy K, New L. Discrepant toxoplasma latex agglutination test results. $J$ Clin Pathol $1989 ; 42: 200-203$.

16. Johnson J, Duffy K, New L, Holliman RE, Chessum BS, Fleck DG. Direct agglutination test and other assays for measuring antibodies to Toxoplasma gondii. J Clin Pathol 1989; 42: $536-541$.

17. Remington JS, Desmonts G. Toxoplasmosis. In : Remington JS Klein JO (eds) Infectious diseases of the fetus and newborn infant, 3rd edn. Philadelphia, WB Saunders. 1990: 89-195.

18. McLeod R, Mack DG. Secretory IgA specific for Toxoplasma gondii. J Immunol 1986; 136: 2640-2643.

19. Stepick-Biek P, Thulliez P, Araujo FG, Remington JS. IgA antibodies for diagnosis of acute congenital and acquired toxoplasmosis. $J$ Infect Dis 1990; 162: 270-273.

20. Desmonts G, Couvreur J. Congenital toxoplasmosis. A prospective study of 378 pregnancies. $N$ Engl J Med $1974 ; 290$ : 1110-1116.

21. Derouin F, Sulcebe G, Ballet JJ. Sequential determination of IgG subclasses and IgA specific antibodies in primary and reactivating toxoplasmosis. Biomed Pharmacother 1987; 41: $429-433$. 